\title{
CHEFS' AWARENESS TOWARDS FOOD STORAGE HIERARCHY IN EGYPTIAN RESTAURANTS
}

\section{AHMED ANWAR ELSAED \\ MOHAMMED ALAA IBRAHIM \\ FACULTY OF TOURISM AND HOTELS , MANSOURA UNIVERSITY, EGYPT}

\begin{abstract}
This research aims to measure the awareness of chefs towards the hierarchy of food storage and analyze the differences between their awareness based on their demographic data. Literature review includes some topics about food storage in the restaurant such as dry storage, chemical storage, refrigerator storage, and freezer storage, food contamination during food storage, preventing cross-contamination during storage, food contaminations and their impact on health, food hierarchy chart in a restaurant, and chefs' awareness towards food hierarchy. For achieving the research aim, an electronic questionnaire (as a test) was designed and distributed to a random sample of chefs in Egyptian restaurants, which 447 responses were received and valid to analyze by SPSS V.25. Results indicated that investigated chefs haven't enough awareness of food hierarchy storage. Some chefs store food in the wrong arrangement that leads to rapid spoilage or cross-contamination. Based on the results, some recommendations have been proposed to increase the awareness of chefs towards food hierarchy storage. One of the most important recommendations was putting guidelines and instructions in clear places within each store that directs chefs on how to arrange food properly.
\end{abstract}

KEYWORDS: Chefs' Awareness, Food Storage Hierarchy , Food Safety, Cross Contamination.

\section{INTRODUCTION}

Proper food storage helps maintain the quality of the food by retaining flavor, color, texture, and nutrients, while reducing the chance of contracting a foodborne illness (Kuijt, 2009). It be noticed that refrigerator temperatures don't destroy pathogenic or spoilage microorganisms, but it slows the growth of microorganisms already in the food (Terpstra et al., 2005). Food must be adequately refrigerated to ensure that it is safe for use and prevent the spread of unhealthy raw bacteria ready for its use (Langiano et al., 2012). Cross-contamination could occur when raw food 
touched or dripped onto prepared or ready-to-eat food (Brown et al., 2013); these food contaminants transmit to humans various diseases that pose varying degrees of threat to human health and life (Karim et al., 2018). Clearly, the wrong arrangement of food will stimulate the production of pathogens and increasing the risk of foodborne illness. Shelves in refrigerator storages counted from the lowest cooking temperature such as ready to eat food to the highest such as raw meat, poultry and fish (Petty, 2015). The hierarchy of food storage is also important, as cooked or ready-to-eat foods should be stored over raw meat, poultry and fish. This will prevent raw product juices from spilling onto the prepared food and causing a foodborne illness (State Food Safety, 2020).

The research's problem is that the concept of food hierarchy is refers to the correct arrangement of food in refrigerator storages. Meanwhile, arranging food items during storage incorrectly by chefs will expose food to crosscontamination and leads to more losses in the restaurant. Accordingly, the research aims to measure the awareness of chefs' towards the hierarchy of food storage and determine whether there is a difference in the awareness of chefs' back to their demographic data (educational type, educational level, years of experience, or job level). The research's significance is that the study is a good source and opportunity for chefs to measure their awareness towards food hierarchy storage, and increasing the awareness of chefs contributes significantly to maximize the profits of the restaurant and reducing losses resulting from food spoilage. The field study has done in 5 months "from 15 March 2020 to 10 August 2020".

\section{RESEARCH HYPOTHESIS}

Based on the researcher's reading about the subject of food hierarchy storage, the research hypothesis suggested as follows:

- There are significant differences on 0.05 degree between the awareness of chefs about food storage hierarchy in Egyptian restaurants according to their demographical data ("H 1.1 " educational type, "H 1.2 " educational level, "H 1.3" years of experience, and "H 1.4" job level). 


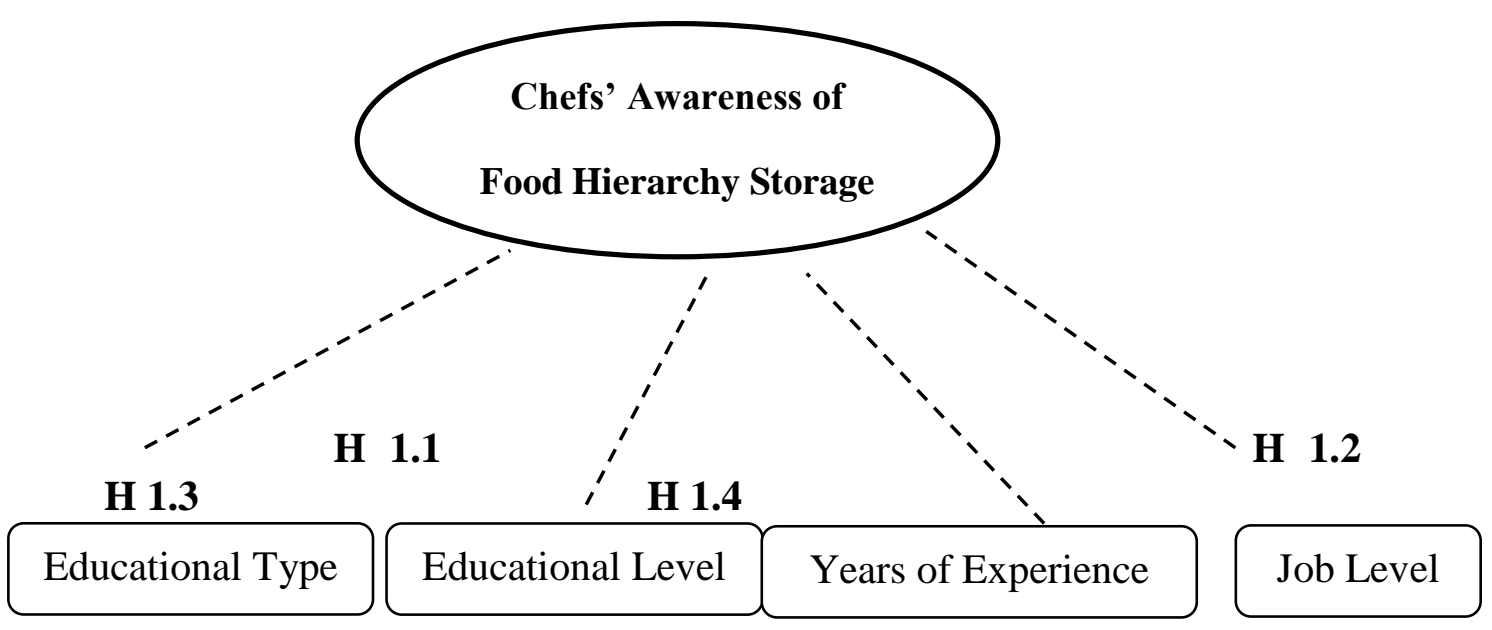

Figure 1: Research Hypothis

\section{LITERATURE REVIEW:}

\section{FOOD STORAGE IN RESTAURANTS}

According to Kuijt (2009), food storing helps in preserving the consistency of the food by preserving taste, color, texture, and nutrients while reducing the risk of contracting a foodborne disease. Food is classifiable into three categories. The first category of perishable food includes meat, poultry, fish, milk, eggs, and several raw vegetables and fruits. Perishable foods should be stored in refrigerator or freezer stores to prevent spoilage, Semiperishable food, such as rice, vegetables, dried fruit, and dry recipes, Nonperishable foods include rice, dried beans, spices, and canned foods that should be stored in dry storage. (Schmitz and Kennedy, 2016).

Restaurants provide four types of food storages: dry storage, chemical storage, refrigerator storage, and freezer storage. Dry storage must be cleaned regularly, dried, darkened, and cold. For dry and canned products, the optimum temperature range is between $10-21{ }^{\circ} \mathrm{C}$. Temperatures above $38^{\circ} \mathrm{C}$ will cause canned food to ruin and lose consistency (Terpstra et al., 2005). Use a recycling strategy first in, first out "FIFO", to keep food from spoiling and keep an eye on use-by dates as well. Products closed to their expiration date should be used first and discard products if they have passed their use-by or expiration dates. All potentially hazardous, ready-toeat food stored in refrigeration at $5^{\circ} \mathrm{C}$ should be discarded if not consumed within 7 days of preparation. Potentially hazardous, ready-to-eat food that has been frozen should be discarded if not consumed within 24 hours of being thawed (Zorba and Kaptan, 2011). According to FIFO, older canned 
and dry food products should be used before ordering new items (Osaili, 2013). Chemical storage that contains cleaning tools and chemicals should be kept in their storage area. It is preferred to store these supplies away from food in clean, dry rooms or in cabinets that can be locked (Boyer and McKinney, 2018).

Referring to refrigerator storage, low temperatures don't kill pathogens or microorganisms but prevent their development that causes food spoilage. (Masson et al., 2017). Perishable food can deteriorate due to spoilage by microorganisms, toxins, and oxidation, even at temperatures in the refrigerator. Time and temperature are the main influences in the consistency of food (Al-Kandari et al., 2019). The low temperature of the refrigerator is the bottom shelf and the coldest region of the refrigerator is normally the place closest to the freezer tank (Boyer and McKinney, 2018). Using food quickly, and prevent it stay long period out of refrigerator as possible. A refrigerator thermometer helps to measure the temperature inside the refrigerator store. Uncovered dishes could cause odors to the refrigerator, dried-out vegetables, nutrient loss, and growth of molds (Schmitz and Kennedy, 2016).

As for freezer storage, Morgan et al., (2017) indicated that adjusting the freezer at under zero degrees preserves stored frozen food, which often would be better quality longer if the temperature of the refrigerator is $23^{\circ} \mathrm{C}$ to $-28^{\circ} \mathrm{C}$. Apart from that, stored frozen food will lose color, texture; taste, and nutritional content but will not cause foodborne disease, which several items made for frozen food storage, like foil, kitchen roll, or boxes, freezer paper, and airtight containers. If food pulled from the freezer has dry, dried-out spots, this means the food has had a freeze burn. Freezer burning means insufficient wrapping allowing air to dry out the surface of the product. While freezer-burned food will not cause sickness, but when eaten it could be tough or distasteful (Terpstra et al., 2005).

\section{FOOD CONTAMINATION DURING FOOD STORAGE}

Cross-contamination arises as disease-transmitting microorganisms passed from one food or surface to some other, borne by utensils, hands, or other objects (Rane, 2011). Cross-contamination, for instance, may occur when raw food (such as chicken) is touched or spilled on cooked or ready-to-eat food (such as lettuce) or food is processed in containers that haven't been adequately cleaned and sanitized and it could even happen in a lot of other ways (Brown et al., (2013). Cross-contamination has several types: Microbiological pollutants include the microorganisms present on the atmosphere, especially in the "hands, fingers, and skin" of people, 
approximately $(100,000)$ bacteria on every square centimeter of human skin. (World Health Organization "WHO", 2015). Chemical contaminants may be in the presence of organic toxins, metals, and contaminants to the environment, pesticides, cleaning chemicals, and food additives that are misused (Rane, 2011). Physical contaminants are visible contamination can be everyone could be seen clearly, that isn't part of the product initially (Institute of Agriculture and Natural Resources "IANR ", 2017).

Brown et al., (2013) agreed with Zorba and Kaptan (2011) that there are many requirements to avoid cross-contamination while storage food, which include:

- Store food in suitable containers. When food removed from its original packaging, cover it in a new, sanitized bag. The new package must be labeled with the name of the product and the date of initial use or expiration.

- Stock raw beef, poultry, and fish separately from ready to eat food. If such items can't be kept individually, store them ready to eat or frozen food below.

- Fresh meat, poultry, and seafood could keep in the refrigerator store in the correct top-to-bottom order: whole seafood, entire beef and pork cuts, cooked meat and fish, and whole and processed poultry.

- Cover fully package food with strong plastic wrap or aluminum foil before freezing it. If food left uncovered, it will lead to crosscontamination. Enticing food for rodents and more vulnerable to cross contamination is food left out in the open

- To prevent cross-contamination, it shouldn't be stored meat above any other food.

\section{FOOD STORAGE HIERARCHY PRACTICES IN RESTAURANTS}

According to (Terpstra et al., 2005) trained chefs in restaurants is decreasing the risk of foodborne disease outbreaks, which experience of food handlers is key in distinguishing between being clean and healthy largely because seeing something looking clean doesn't mean it is healthy. Al-Kandari et al., (2019) found that the presence of trained chefs lead to reduce the risk of transmission of bacteria from the hands to the food. The chefs' awareness of food storage hierarchy helps improve their behaviors; while some chefs haven't been informed that they are specifically responsible for ensuring safety during storing food. This illustrates that these chefs need instruction to understand they are the first line of food safety during storage (Garayoa et al., 2014). The shelves should be numbered from lowest temperature to highest cooking temperature. This aims to prevent juices liquid from contaminating cooked food (Petty, 
2015). The figure below shows a hierarchy of the food to be stored on each shelf.

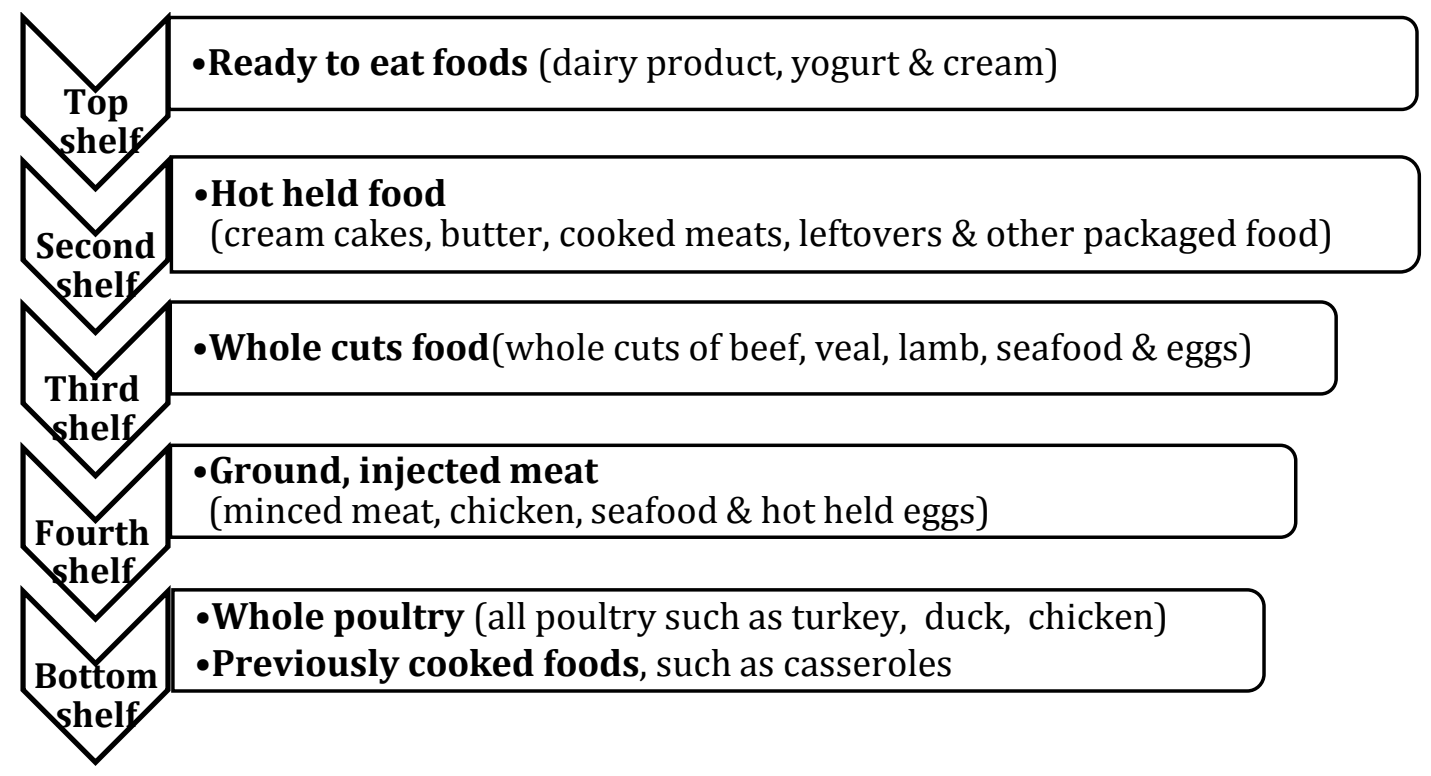

Figure 2: Food storage hierarchy Chart

Source: Developed by the Researcher based on (Petty, 2015; State Food Safety, 2020)

According to Petty (2015) and State Food Safety (2020), arrangement process during storage depends on the temperature of food cooking. Lower cooking temperature food arranged in the highest shelf, meanwhile the highest cooking temperature food arranged in the last shelf. Top Shelf reserved for Ready-to -Eat food. This food could be eaten without first being prepared. Second Shelf: $57^{\circ} \mathrm{C}$ this category contains hot-held food that not found in other categories. Third shelf: $63{ }^{\circ} \mathrm{C} \mathrm{Food}$ that prepared at $63{ }^{\circ} \mathrm{C}$ including entire seafood; entire cuts of beef, veal, lamb; and cooked eggs. Fourth Shelf: $68{ }^{\circ} \mathrm{C}$ it is important to hold on lower shelf meat that has been roasted, processed, or tenderized. Often included in this group are eggs. Bottom shelf: $74{ }^{\circ} \mathrm{C}$ Food with the highest cooking temperatures should be on the lower shelf. This covers all poultry (turkey, duck, and chicken); stuffing containing food requiring temperature control; dishes of food already prepared, such as casseroles.

Langiano et al., (2012) mentioned that the hierarchy of the food in the refrigerator is as follows: Top and middle shelf: Ready-to-Eat food such as dairy products, fast food, processed food, leftovers, grilled meats, and prepared salads. To prevent contamination, they should all be wrapped or contained in enclosed containers. Ready-to-eat food should be kept 
separately from fresh food at the top of the refrigerator so that unhealthy bacteria do not move from the raw food to the cooked food. Bottom shelf: in enclosed containers raw beef, poultry, and fish to protect them from hitting or dripping onto other food. To avoid cross-contamination, raw meats should always be kept at the bottom of the refrigerator. Make sure that each something is packaged or in a closed container, so that other items don't come into contact. Salad stand: Fruit and vegetables that were washed before to storage. It is preferred to make sure the fruit and leafy vegetables like lettuce are wrapped with air holes in paper or plastic to prevent them from pollution. In addition to that, the vegetables should be covered in a wet paper towel before storage such as salads and herbs to avoid them from drying out and to keep them fresh for a long (Lee et al., 2015).

Often essential is the hierarchy of storage in a refrigerator, according to Zorba and Kaptan (2011) store cooked or ready-to-eat food above raw meat, poultry, and fish if these items are stored in the same shelves unit. Store raw meat, poultry, and fish in the following order from top to bottom: whole fish, whole cuts of beef, ground meat and fish, and ground poultry. This order is based on the required minimum internal cooking temperature of each food (Langiano et al., 2012). Wrap raw cuts of meat, especially ground beef, so they are airtight. Meat will turn brown when exposed to air, so frozen meat should be wrapped in airtight, moistureproof material or placed in containers to prevent freezer burn (Lee et al., 2015; Petty, 2015).

\section{RESEARCH METHODOLOGY}

To achieve the research aim, chefs in restaurants were surveyed. The sample equation was applied to unlimited society (Thompson, 2012) as follows:

$$
\left.n=\frac{N \times p(1-p)}{\left[\left[N-1 \times\left(d^{2} \div z^{2}\right)\right]+p(1-p)\right.}\right]
$$

$\mathbf{N}$ : Sample size, P: Percentage of the purpose of this study 0.50 , d: Percentage of the error limit allowed $0.05, \mathbf{Z}$ : The standard degree used for giving general results is $95 \%$. Thus, the standard degree $=1.96$

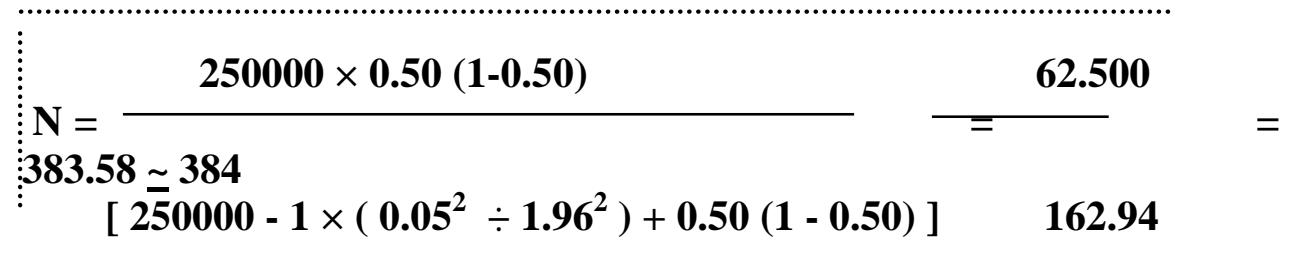


The population of the study is unlimited due to the difficulty of determining a specific number of chefs in Egyptian restaurants, so the random sample size is an ideal method to apply in this study. According to Thompson, (2012) the lower limit of respondents, that suitable in this study are 348. 447 electronic questionnaires (as a test) were designed and distributed from 15 March 2020 to 10 August 2020. The questionnaire consisted of two sections. The first section intended to reveal the chefs' demographic data. The second section intended to determine the chefs' awareness of food storage hierarchy. The respondents were asked to answer these statements by using a two-point Likert-type scale (Yes-No). The Statistical Package for the Social Sciences (SPSS) version 25.0 was used to analyze data. Afterwards their answers classified to (Don't Know= 1, Know =2). The level of agreement range was calculated as follow:

$$
\begin{gathered}
\text { Range }=(\mathbf{2}-\mathbf{1}) \div \mathbf{2}= \\
\mathbf{0 . 5 0} \\
\text { Don't Know }=1 \text { to } 1.50 \\
\text { Know }=1.51 \text { to } 2
\end{gathered}
$$

Table 1: Questions Answered Scale

\begin{tabular}{|c|c|c|}
\hline Category & Don't Know & Know \\
\hline Code & 1 & 2 \\
\hline Range & $1-1.50$ & $1.51-2$ \\
\hline
\end{tabular}

RELIABILITY ANALYSIS

Table 2: Reliability Analysis

\begin{tabular}{|c|c|}
\hline Number of Statements & Alpha \\
\hline 20 & 0.76 \\
\hline
\end{tabular}

Table 2 indicated that alpha coefficient of the questionnaire statements was 0.76 (higher than 0.70) (Pallant, 2016). This result indicated the reliability and validity of the questionnaires for using in the study.

\section{RESUlTS AND DISCUSSION}

The results involved three two stages. Descriptive analysis was used to discover participants' responses, variance analysis for respondents' answers were conducted to examine the relationship between independent variables, and dependent variable. The results obtained were computed and analyzed in the following tables. 
Table 3: Demographic data of chefs

\begin{tabular}{|c|c|c|c|c|c|c|c|}
\hline \multirow{2}{*}{ Demographic Data } & \multirow{2}{*}{ Attribute } & \multicolumn{2}{|c|}{ Statistics } & \multirow{2}{*}{ Demographic Data } & \multirow{2}{*}{ Attribute } & \multicolumn{2}{|c|}{ Statistics } \\
\hline & & Freq. & $\%$ & & & Freq. & $\%$ \\
\hline \multirow{6}{*}{ Educational level } & Below average & 8 & 1.8 & \multirow{4}{*}{$\begin{array}{c}\text { Years of } \\
\text { experience }\end{array}$} & $>1$ year & 68 & 15.2 \\
\hline & Average & 139 & 31.1 & & $<1-5$ years & 112 & 25.1 \\
\hline & Institutional & 95 & 21.3 & & $<5-10$ years & 92 & 20.6 \\
\hline & University & 193 & 43.2 & & $<10$ years & 175 & 39.1 \\
\hline & \multirow{2}{*}{ Postgraduate } & \multirow{2}{*}{12} & \multirow{2}{*}{2.7} & \multirow{5}{*}{ Job level } & Operational & 165 & 36.9 \\
\hline & & & & & Supervisory & 146 & 32.7 \\
\hline \multirow{3}{*}{ Educational type } & Hotel & 257 & 57.5 & & & & \\
\hline & General & 190 & 42.5 & & Administrative & 136 & 30.4 \\
\hline & Total & 447 & 100 & & Total & 447 & 100 \\
\hline
\end{tabular}

"Freq." Frequency

" less than

" more than 
As it can be observed from table 3 that, among the 447 respondents, a high proportion of the tested sample (43.2\%) have a university educational degree and (31.1\%) were have average education "vocational/secondary school degree", it was followed by chefs whose have an institutional qualification with $(21.3 \%)$ and $(2.7 \%)$ were have postgraduates degree "Diploma-Master-Ph.D.". Chefs with below-average education "Primary-Preparatory-without" were the smallest group and presented by $(1.8 \%)$. This result shows that chefs seek to obtain a university degree to help them with their career in restaurants. Concerning type of education, (57.5\%) of respondents have studied a hotel education, while it appeared by $(42.5 \%)$ have studied a general education. This result demonstrates that the majority of chefs with a hotel education realize that it will help them in their specialty. According to years of experience, a high proportion of the tested sample $(39.1 \%)$ were More than 10 years, while $(25.1 \%)$ were more than $1-5$ years and $(20.6 \%)$ were more than 5-10 years. chefs with less than 1 years of experience were the smallest group and presented by (15.2\%). In connection with job level, percentages were very close which $(36.9 \%)$ was operational level "from third to first chef", while (32.7\%) was supervisory level "Assistant head chef - Head chef" and (30.4\%) was administrative level "Assistant executive chef Executive chef".

Table 4: Chefs' awareness towards food hierarchy storage

\begin{tabular}{|l|c|c|c|c|c|c|}
\hline \multicolumn{1}{|c|}{ Attributes } & $\overline{\mathbf{x}}$ & $\mathbf{S D}$ & $\begin{array}{c}\mathbf{C V} \\
\mathbf{\%}\end{array}$ & $\mathbf{R}$ & T-test & sig. \\
\hline lower shelf in refrigerator store is the lowest temperature & 1.58 & .494 & 31 & 10 & 65.57 & $.000 *$ \\
\hline New food stores behind old food on the same shelf & 1.70 & .457 & 27 & 5 & 76.60 & $.000 *$ \\
\hline Broccoli stores beside green apples & 1.37 & .482 & 35 & 14 & 57.70 & $.000 *$ \\
\hline Salad stores alongside a fruit salad & 1.22 & .417 & 34 & 16 & 59.48 & $.000 *$ \\
\hline
\end{tabular}




\begin{tabular}{|l|l|l|l|l|l|l|}
\hline Chicken pane stores alongside the shrimp pane & 1.21 & .406 & 34 & 18 & 60.25 & $.000 *$ \\
\hline Canned fruits such as compote stores below brioche & 1.50 & .500 & 33 & 12 & 61.89 & $.000 *$ \\
\hline $\begin{array}{l}\text { The coldest part of the refrigerator store is the part closest to } \\
\text { the freezer unit. }\end{array}$ & 1.72 & .450 & 26 & 4 & 78.30 & $.000 *$ \\
\hline English cake and bakeries stores above lamb cuts & 1.17 & .372 & 32 & 20 & 63.39 & $.000 *$ \\
\hline $\begin{array}{l}\text { Opened food containers such as canned tomatoes stores in } \\
\text { refrigerator store }\end{array}$ & 1.21 & .405 & 33 & 19 & 60.38 & $.000 *$ \\
\hline \begin{tabular}{l} 
Raw meat stores on the first shelf in the refrigerator store \\
\hline Dairy products stores in the refrigerator's lower shelf
\end{tabular} & 1.61 & .489 & 30 & 8 & 67.27 & $.000 *$ \\
\hline Casseroles and sauces stores on the same shelf & 1.62 & .487 & 30 & 7 & 68.11 & $.000 *$ \\
\hline Boiled eggs stores on top of raw eggs & 1.79 & .406 & 23 & 2 & 90.63 & $.000 *$ \\
\hline $\begin{array}{l}\text { Ground meat stores alongside cold cuts such as luncheon and } \\
\text { pastrami }\end{array}$ & 1.78 & .417 & 23 & 3 & 87.48 & $.000 *$ \\
\hline Cake stores on the lower shelf of yogurt & 1.61 & .489 & 30 & 9 & 67.43 & $.000 *$ \\
\hline Chicken strips stores alongside whole chicken & 1.33 & .471 & 35 & 15 & 57.49 & $.000 *$ \\
\hline
\end{tabular}




\begin{tabular}{|l|c|c|c|c|c|c|}
\hline Chicken stores alongside leafy vegetables & 1.80 & .403 & 22 & 1 & 91.60 & $.000 *$ \\
\hline All vegetables and fruits stores in refrigerator store & 1.22 & .417 & 34 & 17 & 59.49 & $.000 *$ \\
\hline Soup stores in the middle of the refrigerator & 1.46 & .499 & 34 & 13 & 59.85 & $.000 *$ \\
\hline Cheese stores on the lower shelf & 1.54 & .499 & 32 & 11 & 62.98 & $.000 *$ \\
\hline Average of Responses & $\mathbf{1 . 5 0}$ & $\mathbf{0 . 4 5}$ & $\mathbf{3 0}$ & --- & ---- & ---- \\
\hline
\end{tabular}

$\mathbf{N}=447 \quad \overline{\mathbf{x}}$ : Mean $\quad$ SD: Standard Deviation $\quad$ CV: Coefficient Variance $(\mathbf{S D} \div \overline{\mathbf{x}} \%) \quad$ R: Rank $\quad$ Test value $=(0.05)$ $*$ sig. $\leq(.05)$ 
The results in Table 4 show that the respondents have not awareness enough about food storage hierarchy, as the average mean was 1.50 . Besides, the results show that there are significant differences among respondents towards the attributes of the table above which $p$-value $\leq(.05)$. The previous table shows that chefs have knowledge about food storage hierarchy (mean $=1.51-2)$ in the following statements:

1. Chicken stores alongside leafy vegetables (mean $=1.80, \mathrm{CV}=22 \%$ ).

2. Boiled eggs stores on top of raw eggs (mean $=1.79, \mathrm{CV}=23 \%$ ).

3. Ground meat is stores alongside cold cuts such as luncheon and pastrami (mean=1.78, CV=23\%). This statement and the one before are the opposite of that mentioned in the chart of food storage hierarchy (Petty, 2015; State Food Safety, 2020).

4. The coldest part of the refrigerator store is the part closest to the freezer unit. (mean $=1.72, \mathrm{CV}=26 \%$ ). This statement agreed with Boyer and McKinney (2018), who mentioned that the coldest region of the refrigerator is normally the place closest to the freezer tank.

5. New food are stores behind old food on the same shelf in the refrigerator store (mean $=1.70, \mathrm{CV}=27 \%$ ). This belief coincides with the view explained that using a recycling strategy "FIFO" older food products can be used before new items (Boyer and McKinney, 2018).

6. Casseroles and sauces are stores on the same shelf (mean=1.66, $\mathrm{CV}=28 \%$ ). This statement is consistent with Petty (2015), which claimed that the lower shelf covers all poultry and dishes of food already prepared, such as casseroles and sauces.

7. Dairy products are stores in the refrigerator's lower shelf (mean=1.62, $\mathrm{CV}=30 \%$ ). Langiano et al., (2012) explained that dairy products must be stored on the top shelf.

8. Raw meat is stores on the first shelf in the refrigerator store (mean=1.61, CV=30\%). According to Koppel (2016), to avoid crosscontamination, raw meats could always is kept at the bottom of the refrigerator.

9. Cake stores in the lower shelf of yogurt (mean $=1.61, \mathrm{CV}=30 \%$ ). This statement agreed with the chart of food storage hierarchy (Petty, 2015; State Food Safety, 2020).

10. The lower shelf in the refrigerator store is the lowest temperature (mean $=1.58, \mathrm{CV}=31 \%$ ). This result agreed with Boyer and McKinney (2018), who explained that the low temperature of the refrigerator is the bottom shelf.

11. Cheese stores on the lower shelf (mean $=1.54, \mathrm{CV}=32 \%)$. 
On other hand the previous table also shows that chefs haven't knowledge about food storage hierarchy (mean $=1-1.50$ ), as their answers were not correct in 9 statements as follows:

1. Broccoli stores beside green apples (mean $=1.37, \mathrm{CV}=0.35$ ).

2. Salad stores alongside a fruit salad (mean $=1.22, \mathrm{CV}=0.34$ ). Zorba and Kaptan (2011) stated that cooked or ready-to-eat food like vegetables and fruits are stored on the same shelves.

3. Chicken pane stores alongside the shrimp pane (mean $=1.21, \mathrm{CV}=$ $0.34)$.

4. English cake and bakeries stores above lamb cuts (mean $=1.17, \mathrm{CV}=$ 0.32 ).

5. Chicken strips stores alongside whole chicken (mean $=1.33, \mathrm{CV}=0.35$ ). The statement "3,4" agrees while the statement "5" opposes according to food storage hierarchy chart (Petty, 2015; State Food Safety, 2020).

6. Canned fruits such as compote stores below brioche (mean $=1.50, \mathrm{CV}=$ 0.33). This result in contrast with Terpstra et al., (2005) who reported that dry storage shouldn't stores with non-perishable food such as canned products.

7. Opened food containers such as canned tomatoes and fruits are store in refrigerator stores (mean $=1.21, \mathrm{CV}=0.33$ ). This statement in contrast with Koppel (2016), who found that open cans can't store in the refrigerator because chemicals, particularly acidic food such as fruit and tomatoes, can be polluted.

8. All vegetables and fruits store in refrigerator store (mean $=1.22, \mathrm{CV}=$ $0.34)$.

This statement is the opposite of what Kuijt (2009) noticed that nonperishable food include rice, nuts several raw vegetables and fruits stored in dry storage, meanwhile Semi-perishable food such as

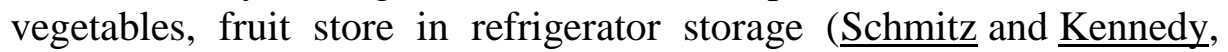
2016).

9. Soup is stores in the middle of the refrigerator, (mean $=1.46, \mathrm{CV}=$ 0.34). This result in contrast with Petty (2015) who reported that soup and hot-held food stored on the second shelf of the refrigerator. 


\section{TESTING HYPOTHESES}

Table 5: T-Test \& One-Way ANOVA Test / Post Hoc Multiple Comparisons

\begin{tabular}{|c|c|c|c|c|c|c|c|c|}
\hline \multirow{2}{*}{$\begin{array}{c}\text { Demographic } \\
\text { Data }\end{array}$} & \multicolumn{3}{|c|}{ Scheffe Post Hoc } & \multirow{2}{*}{ df } & \multirow{2}{*}{ CI } & \multirow{2}{*}{$\begin{array}{l}\text { T- } \\
\text { Test }\end{array}$} & \multirow{2}{*}{$\mathbf{F}$} & \multirow{2}{*}{ Sig. } \\
\hline & Factors & $\mathbf{N}$ & $\overline{\mathbf{x}}$ & & & & & \\
\hline \multirow{2}{*}{$\begin{array}{c}\text { Educational } \\
\text { type }\end{array}$} & Hotel & 257 & 1.52 & \multirow{2}{*}{446} & \multirow{2}{*}{0.95} & \multirow{2}{*}{58.742} & \multirow{2}{*}{------- } & \multirow{2}{*}{$.000 *$} \\
\hline & General & 190 & 1.50 & & & & & \\
\hline \multirow{5}{*}{$\begin{array}{c}\text { Educational } \\
\text { level }\end{array}$} & Below average & 8 & 1.48 & \multirow{5}{*}{446} & \multirow{5}{*}{------- } & \multirow{5}{*}{------- } & \multirow{5}{*}{1.174} & \multirow{5}{*}{.334} \\
\hline & Average & 139 & 1.51 & & & & & \\
\hline & Institutional & 95 & 1.53 & & & & & \\
\hline & University & 193 & 1.50 & & & & & \\
\hline & Postgraduate & 12 & 1.49 & & & & & \\
\hline \multirow{3}{*}{$\begin{array}{c}\text { Years of } \\
\text { experience }\end{array}$} & $>1$ years & 68 & 1.45 & \multirow{3}{*}{446} & \multirow{3}{*}{------- } & \multirow{3}{*}{------- } & \multirow{3}{*}{7.272} & \multirow{3}{*}{$.000 *$} \\
\hline & $<1-5$ years & 112 & 1.49 & & & & & \\
\hline & $<5-10$ years & 92 & 1.51 & & & & & \\
\hline
\end{tabular}


International Journal of Tourism and Hospitality Management Volume 3, Issue 2, December 2020

\begin{tabular}{|c|c|c|c|c|c|c|c|c|}
\hline & $<10$ years & 175 & 1.54 & & & & & \\
\hline \multirow{3}{*}{ Job level } & Operational & 165 & 1.47 & \multirow{3}{*}{446} & \multirow{3}{*}{------ } & \multirow{3}{*}{------- } & \multirow{3}{*}{9.532} & \multirow{3}{*}{$.000 *$} \\
\hline & Supervisory & 146 & 1.51 & & & & & \\
\hline & Administrative & 136 & 1.54 & & & & & \\
\hline
\end{tabular}


With regard to education dimension Table 5 clarifies that the results of TTest for two independent samples showed that there is a significant difference among chefs' awareness towards food storage hierarchy back to the educational type, which t-test (55.742) and P-value (.000) "less than $0.05 "$. This result clarifies the variation between the respondents according to educational type. Referring to Scheffe Post Hoc, chefs who have studied a hotel education (mean=1.52) more awareness of food storage hierarchy than those who have studied a general education (mean=1.50). this result agreed with Al-Kandari et al., (2019) found that qualified and trained chefs lead to reduce the risk of transmission of bacteria from the hands to the food. The results of One-Way ANOVA test showed that there are no significant differences among the awareness of chefs about food storage hierarchy in the restaurants returns to their educational level, which $\mathrm{F}$ value (1.174), and P-value (.334) "more than 0.05".

Moreover, there is a significant difference among chefs in awareness of food storage hierarchy refers to years of experience, which $F$ value (7.272) and P-value (.000) "less than 0.05". According to Scheffe Post Hoc result, chefs who have less than 1 year experience (mean= 1.45) have less awareness of food hierarchy storage, meanwhile chefs who have more than $1-5$ years' experience $($ mean $=1.49)$ and more than 10 years' experience (mean=1.54) have more awareness of food hierarchy storage. This result confirms if the number of chefs' experience years increased, chefs' awareness would increase towards food hierarchy storage.

Finally, there is a significant difference among chefs' awareness towards food storage hierarchy back to the job level, which F value (9.532) and Pvalue (.000) "less than 0.05". The Scheffe Post Hoc result indicates that chefs who work on an operational level (mean $=1.47)$ have less awareness of food hierarchy storage, meanwhile chefs who work on a supervisory level (mean= 1.51), and administrative level (mean= 1.54) have more awareness of food hierarchy storage. This result reveals the job level of chefs' effects on food storage hierarchy in restaurants and confirms that administrative chefs "Assistant executive chef - Executive chef" should be have an essential role in increasing operational chefs' awareness of food storage hierarchy.

\section{Conclusion}

This paper has presented an investigation into determining the chefs' awareness towards food storage hierarchy in Egyptian restaurants. Chefs do not have sufficient awareness of the food storage hierarchy, and this 
may be a major reason for taking negative actions about the incorrect arrangement of food storage.

With regard to analyze chefs' awareness towards food hierarchy storage, the majority of chefs didn't know the correct food hierarchy storage, which the average of respondents' answers was incorrect in some statements such as chicken strips stores alongside whole chicken, opened food containers like canned tomatoes and fruits stores in refrigerator store, and soup stores in the middle of a refrigerator. On the other side, the chefs' answers were correct despite contradictory wording of some statements such as raw meat stores on the first shelf in the refrigerator store to prevent crosscontamination, dairy products stores in the refrigerator's lower shelf, boiled eggs stores on top of raw eggs, ground meat stores alongside cold cuts such as luncheon and pastrami, and chicken stores alongside leafy vegetables.

Finally, there is a significant variance of demographic data for chefs (educational type, years of experience, and job level) on chefs' awareness towards food hierarchy storage. This paper confirms if the education of the chefs is a hotel education and years number of chefs' experience and their job level increased, chefs' awareness would increase towards food hierarchy storage.

\section{ReCOMmendations AdDressed to Restaurants Managements}

According to the literature review and the results extracted from the field study, the following recommendations could be suggested:

1. Putting guidelines and instructions in clear places inside each store, which direct chefs on how to arrange items during food storage.

2. The shelves should be numbered from the lowest temperature to the highest cooking temperature. This aims to guide chefs by food cooking temperature to choose the right arrangement of the food item.

3. Holding discussion sessions with chefs on food storage hierarchy to inform them of the correct arrangement of food storage in the briefing meeting.

4. Design a checklist for the hierarchical storage of food products and it should be reviewed continuously by daily reports provided to the executive chef.

5. Checking stores after each work shift to ensure the correct order of the stored food.

6. Adding the topic of food storage hierarchy to training courses of food safety provided to chefs. 
7. It recommended to restaurant management to hire chefs who have a hotel qualification, as they have more awareness of food hierarchy storage.

\section{REFERENCES}

Al-Kandari, D., Al-abdeen, J., and Sidhu, J., (2019), "Food Safety Knowledge, Attitudes, and Practices of Food Handlers in Restaurants in Kuwait", Food control, 103, 103-110.

Boyer, R. R., and McKinney, J. M. (2018), "Food Storage Guidelines for Consumers", Food Science and Technology, Virginia State University, 18(3) 348-960.

Brown, L. G., Khargonekar, S., Bushnell, L., and Environmental Health Specialists Network Working Group (2013), "Frequency of Inadequate Chicken Cross-Contamination Prevention and Cooking Practices in Restaurants", Journal of food protection, 76(12), 2141-2145.

Food Hygiene Company, (2019), "Tips about Safe Food Storage", Available online on https://www.foodhygienecompany.co.uk/blog/food-hygiene/ 5-every-day-tips-to-remember-about-safe-food-storage/ - Accessed on 18 July 2020.

Garayoa, R., Díez-Leturia, M., Bes-Rastrollo, M., García-Jalón, I. and Vitas, A.I., (2014), "Catering Services and HACCP: Temperature Assessment and Surface Hygiene Control Before and After Audits and a Specific Training Session", Food Control 43, 193-198.

Institute of Agriculture and Natural Resources, n.d. "IANR ", (2017) "Identifying Physical Hazards", University of Nebraska-Lincoln, Available online on http://food.unl.edu/physical.hazards - Accessed on 6 June 2020.

Karim, A. B., Hassan, A. Z., and Akanda, M. M. (2018), "Monitoring Food Storage Humidity and Temperature Data Using Iot", MOJ Food Process Technol, 6(4), 400-404.

Koppel, K., Sosa, M., Gutierrez, N. G., Cardinal, P., Godwin, S. L., Cates, S. C., \& CHAMBERS IV, E. (2016). Consumer Practices for Purchase, Storage, And Preparation of Poultry and Eggs in Selected North and South American Countries: A pilot study. Vitae, 23(1), 58-64.

Kuijt, I. (2009), "What Do We Really Know about Food Storage, Surplus, and Feasting in Preagricultural Communities?" Current Anthropology, 50(5), 641-644.

Langiano, E., Ferrara, M., Lanni, L., Viscardi, V., Abbatecola, A. M., \& De Vito, E. (2012). Food Safety at Home: Knowledge and Practices of Consumers. Journal of Public Health, 20(1), 47-57. 
Lee, S. J., Si, J., Yun, H. S., \& Ko, G. (2015). Effect of Temperature and Relative Humidity on the Survival of Foodborne Viruses during Food Storage. Applied and environmental microbiology, 81(6), 2075-2081.

Masson, M., Delarue, J., and Blumenthal, D. (2017), "An Observational Study of Refrigerator Food Storage by Consumers in Controlled Conditions", Food Quality and Preference, 56, 294-300.

Morgan, A. R., O’Hagan, C., Touchard, S., Lovestone, S., and Morgan, B. P. (2017), "Effects of Freezer Storage Time on Levels of Complement Biomarkers", BMC research notes, 10(1), 559.

Osaili, T. M., Jamous, D. O. A., Obeidat, B. A., Bawadi, H. A., Tayyem, R. F., and Subih, H. S. (2013). "Food Safety Knowledge among Food Workers in Restaurants in Jordan", Food Control, 31(1), 145-150.

Pallant, J. (2016). SPSS survival manual, 6th Ed., Berkshire, McGraw-Hill Education (UK).

Petty. L. (2015), "Do You Know Which Fridge Shelves You Should Store Your Food On?", Available online on https://www. highspeedtraining. co.uk/hub/fridge-shelves-storing-food/ -Accessed on 9 July. 2020.

Rane, S., (2011), "Street Vended Food in Developing World: Hazard Analysis", Indian J. Microbiol 51(1), 100-106.

Schmitz, A. and Kennedy, P.L. (2016), "Food Security and the Role of Food Storage", Food Security in a Food Abundant World (Frontiers of Economics and Globalization, 16 (1), 1-17.

State Food Safety, (2020), "Fridge Storage for Food Safety", Available online onhttps://www.statefoodafety.com/Resources/Resources/fridge-storagefor-food-safety- Accessed on 16 June 2020.

Terpstra, M. J., Steenbekkers, L. P. A., De Maertelaere, N. C. M., and Nijhuis, S. (2005), "Food Storage and Disposal: Consumer Practices and Knowledge", British Food Journal 107 (7), 526-533.

Thompson, S. K., ( 2012) "Sampling", Third Edition, John Wiley \& Sons, Inc, U.S pp. 59-60.

World Health Organization "WHO", (2015), "WHO Estimates of the Global Burden of Foodborne Diseases: Foodborne Diseases Burden Epidemiology Reference Group, 2007-2015", Available online on https://apps.who.int/iris/bitstream/handle/10665/199350/978924156516 5_eng.pdf-Accessed on 5 May 2020.

Zorba, N. N. D., \& Kaptan, M. (2011). Consumer Food Safety Perceptions and Practices in a Turkish Community. Journal of food protection, 74(11), 1922-1929. 